\title{
Digital Teaching Competence in Higher Education: A Systematic Review
}

\author{
José María Fernández-Batanero ${ }^{1, *} \mathbb{E}^{\mathbb{D}}$, Pedro Román-Graván ${ }^{1}\left(\mathbb{D}\right.$, Marta Montenegro-Rueda $^{1}{ }^{\mathbb{D}}$, \\ Eloy López-Meneses ${ }^{2} \mathbb{B}$ and José Fernández-Cerero ${ }^{1}$ \\ 1 Department of Teaching and Educational Organization, University of Sevilla, 41013 Sevilla, Spain; \\ proman@us.es (P.R.-G.); mmontenegro1@us.es (M.M.-R.); jfcerero@us.es (J.F.-C.) \\ 2 Department of Education and Social Psychology, Pablo de Olavide University, 41013 Sevilla, Spain; \\ elopmen@upo.es \\ * Correspondence: batanero@us.es; Tel.: +34-955-42-05-95
}

check for

updates

Citation: Fernández-Batanero, J.M.; Román-Graván, P.; MontenegroRueda, M.; López-Meneses, E.; Fernández-Cerero, J. Digital Teaching Competence in Higher Education: A Systematic Review. Educ. Sci. 2021, 11,689. https://doi.org/10.3390/ educsci11110689

Academic Editors: Eleanor Dommett and Ching Sing Chai

Received: 10 September 2021

Accepted: 26 October 2021

Published: 29 October 2021

Publisher's Note: MDPI stays neutral with regard to jurisdictional claims in published maps and institutional affiliations.

Copyright: (c) 2021 by the authors. Licensee MDPI, Basel, Switzerland. This article is an open access article distributed under the terms and conditions of the Creative Commons Attribution (CC BY) license (https:// creativecommons.org/licenses/by/ $4.0 /)$.

\begin{abstract}
Higher education is one of the educational stages most affected by digital technologies, whose constant development has produced a favourable atmosphere for new approaches regarding the teaching-learning processes. The aim of the study was to identify the most relevant findings that specialists have analysed in terms of the digital competences of university teachers, through the analysis of the scientific production of the specialised literature in the last decade (2009-2019). A search was carried out on the Web of Science (WoS) and Scopus databases following the guidelines of the PRISMA statement (Preferred Reporting Items for Systematic reviews and Meta-Analyses). After applying the inclusion and exclusion criteria, the sample was made up of 20 articles. The main findings show the low level of digital competence among teachers and the need for training in both technological and pedagogical areas.
\end{abstract}

Keywords: digital competence; college faculty; higher education; teachers; systematic review

\section{Introduction}

The incorporation of Information and Communication Technologies (ICT) has called for universities to propose and implement policies that meet these new needs. In this regard, higher education is currently one of the educational stages most affected by digital technologies. ICT's constant progress has generated favourable conditions for new approaches to teaching and learning processes. The universalisation of the internet has helped to create different proposals: smart, digital, wireless, cybernetic or knowledge. Among these terms, smart is the latest development, and it is closely related to the academic world.

This new digital scenario presents some challenges, among which are: the establishment of an innovation culture which includes the use of digital technologies; the comprehensive assessment of learning with the use of digital technologies; and the reorganisation of institutions to properly introduce digital technologies [1]. These challenges have been described in detail by experts in higher education and digital technology, and certain medium and long-term objectives have also been set out in the contemporary education agenda [2]. It is evident that digital technologies provide essential support to learning when it comes to carrying out personalised educational interventions, where some theoretical models have shown their effectiveness, as pedagogical tools that promote creativity. Over the last few years, this has become an emerging field of study.

The literature related to the use of ICT and higher education shows a lack of consensus regarding the definition of digital competences, and although there has been some progress in the conceptualisation, it is complex to define their meaning. The definition of digital competence itself is diverse, multi-faceted and context-based [3]. If we look back, we can see that the European Union already put forward the European Reference Framework for Key Competences for Lifelong Learning in 2004 [4]. This defined digital competence as the 
critical use and utilisation of digital media for learning, work, leisure and communication. Approaches the concept from different angles, and within the teacher's professional competences, different authors refer to those capacities or skills related to the use of technological tools in the classroom as being different from the use that can be given to these tools in one's home environment $[5,6]$. Thus, teachers' digital literacy is presented as essential in relation to ICT knowledge and its integration into the teaching and learning processes [7]. In short, digital teaching competence is related to all those skills, attitudes and knowledge required by teachers in a digitalised world [8].

\section{Research on Digital Teaching Skills within the University Context}

There is not much literature on the challenges imposed by digital technologies in training university teachers. Nevertheless, Mykhnenko [9] argues that the importance of applying learning technologies is now seen not only as an essential part of teachinglearning in higher education, but also as critical evidence of innovative teaching practices.

One aspect of great relevance for university teachers in relation to digital technologies involves their adaptation to and blending with them, which itself is not an easy task, since, among other things, it requires them to become digitally literate, and all that this demands [10]. On the other hand, Ottenbreit, Liao, Sadik \& Ertmer [11] argue that some scholars have suggested that if university teachers have enough strong ICT-related knowledge, they will be able to overcome barriers and thus successfully incorporate technology into their teaching practice.

There are initiatives to incorporate digital technologies systematically into the practice of higher education teachers. Thus, some studies have shown that it often generates certain resistance among teachers and its use ends up being an adaptation of traditional teaching methods. Several studies carried out regarding the self-perception of the university community about the incorporation of digital technologies in educational processes show that the technological and instrumental roles are mainly valued. Digital technologies are not valued in themselves as a transforming element of the teaching dimension [12].

Despite all the above, we can state that, although there are many studies on digital competences in different educational environments, there is still little scientific production in the area of university teaching digital competences. This production needs not only to increase in quantity but also in the range of research designs [13].

\section{Purpose and Research Questions}

The aim of this research was to identify the most relevant scientific literature on the digital competences of university teachers by analysing the scientific literature published between 2009-2019.

In this regard, the following research questions have been addressed:

Q1. What is the state of the scientific production over time?

Q2. Which countries concentrate the greatest scientific production linked to this field?

Q3. What impact has this field had on the scientific community in terms of the number of citations received?

Q4. What types of methodological designs have been used in studies that investigate the digital competence of university teachers?

Q5. What are the challenges that university professors face to improve digital competence according to the results of the study?

\section{Method}

The performance of systematic reviews enables the mapping of available evidence from research studies about a particular theme of interest within time limitations, the analysis of this information and the achievement of results [14]. This study was carried out according to the recommendations of the Preferred Reporting Items for Systematic Reviews and Meta-analyses Statement (PRISMA) [15]. The systematic review was conducted in four phases: 


\subsection{Document Search}

In order to identify relevant studies, two academic databases (WoS and Scopus) were searched using the following keywords, both in English and Spanish: "digital competence" or "digital literacy", and "faculty" and "university" or "higher education". The search for keywords or descriptors was carried out in both English and Spanish in order to avoid publication language bias by limiting searches to a single language. The search was restricted to the last decade, i.e., a date range from January 2009 to December 2019. The choice of databases was based on two main reasons: firstly, the prestige and international recognition of the resources, as they are currently the main sources for locating the most important publications in the field of social sciences. Secondly, and in relation to the sample, it must be said that their representativeness is guaranteed by the consideration of the international prestige of the databases and their requirements in terms of indexing protocols, but also by the specific limitation of a number of search criteria and a definitive procedure.

Likewise, the selection of this population group (university teachers) was relevant for two reasons: firstly, because it has been previously documented in empirical studies that there is a need for more research to be carried out in the field of higher education regarding educational virtualisation, and the levels, models and modalities of education using technology; second, the commitment to develop and strengthen scientific, technological and innovation capacities is achieved, among other things, through technological development, innovation and specialised and high-qualified training of academia and the research community [16].

\subsection{Description of the Selection Criteria Applied to the Texts}

The search conducted in August 2020 initially resulted in a total of 169 references/publications through the combination of the above-mentioned keywords and the selection criteria in the selected databases ( $99 \mathrm{WoS}$ and 70 Scopus). In this first search, 15 publications were also included through manual selection after reviewing the reference lists of the articles. A total of 184 articles were thus obtained.

The following inclusion criteria were applied: (a) research on digital teaching competence in the university context; (b) articles published in peer-reviewed journals; (c) had clearly evidenced methodological design; (d) delimitation of keywords in the title, abstract or keywords; (e) published between the years 2009-2019.

According to the exclusion criteria, the following were eliminated: (a) publications such as books or book chapters, theses, conference proceedings and reports, among others; (b) duplicated articles; (c) articles outside the university context; (d) articles that did not specify a clear research methodology.

After manual review and screening of the articles, 61 articles that were found to be duplicates were removed, yielding a result of 123 articles. For the selection of the material for the review, the different exclusion criteria set out above were applied, and 103 articles were removed. These articles were excluded because of: inadequate context (37 documents), type of document ( 40 documents) and because they did not specify a clear methodology ( 26 documents). Finally, 20 potentially relevant articles were included in the review (Figure 1).

A total of 20 articles published in peer-reviewed journals between 2009 and 2019 met the inclusion criteria and were included in this review.

Table S1 shows a detailed analysis of the articles that were selected for review, indicating all relevant information: author, year, country, research design, main findings and number of citations (Supplementary Material). 


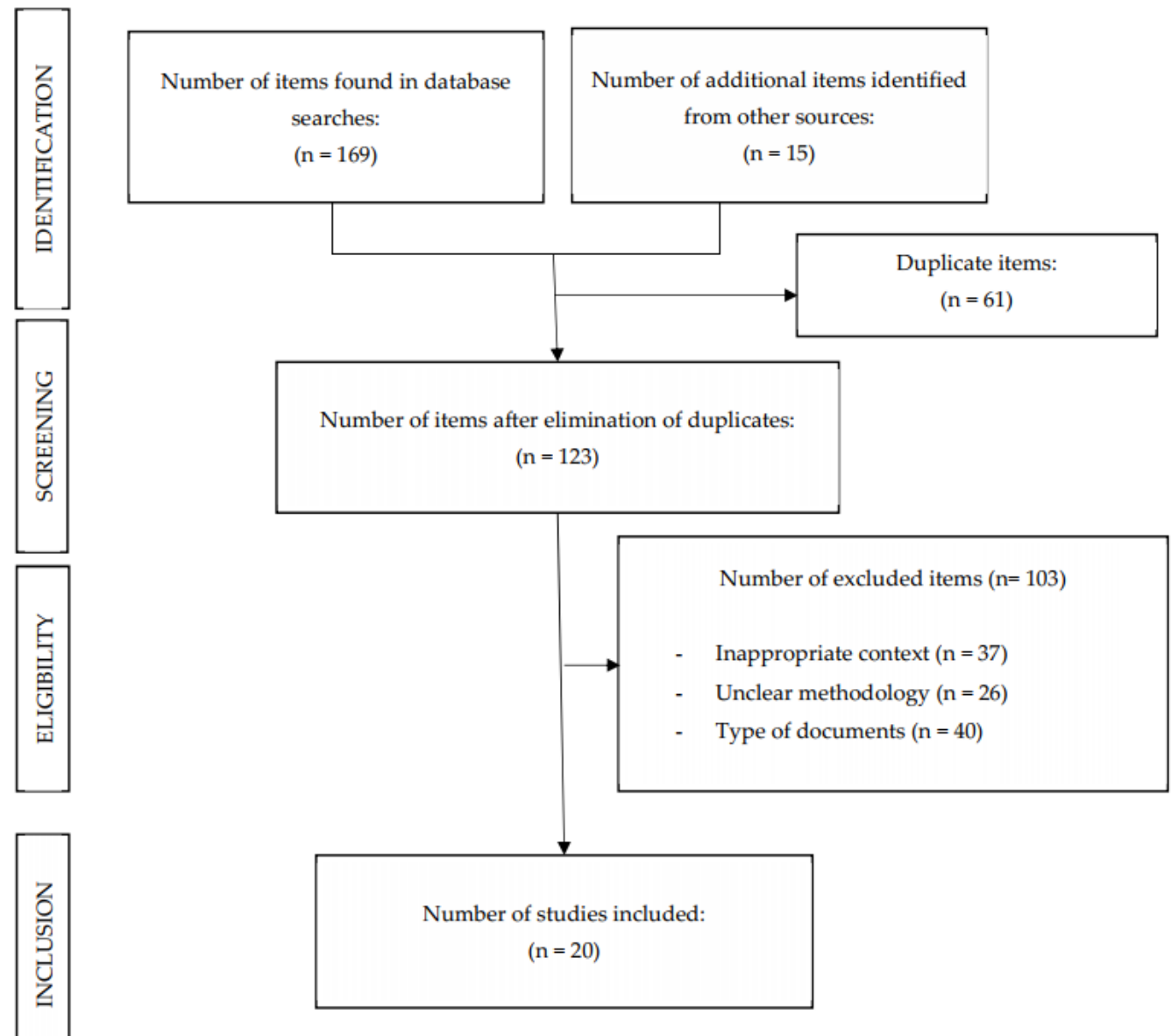

Figure 1. Sample selection flowchart.

\subsection{Analysis and Categorisation Process}

For the analysis and interpretation of the studies developed on digital teaching skills in higher education, descriptive, quantitative and correlational techniques were combined with the semantic application of the study of keywords. The aim of the quantitative analysis was to find out how many publications per year have been made on digital teaching competence in higher education, the countries in which they have been published most, what type of methodological design is most common and what barriers or obstacles hinder the development of these competences. The aim of the qualitative analysis was to describe the most relevant problems regarding digital competences by university teachers, their future lines and the most important challenges.

For the content analysis, the extracted data were entered into a spreadsheet and organised in columns under the following topics or fields: author, title, journal, year of publication, methodology, number of citations and results. Using network analysis [17], an analysis of keywords was carried out in order to identify possible trends that were investigated in this field, with visual representation using the VOSviewer software.

The analysis procedure consisted of coding the selected articles in the database, whose information had been interpolated into graphs and tables. Initially, the articles retrieved from the different sources were loaded and saved in a digital folder stored in the cloud and shared by the researchers. The articles were examined by three researchers independently to refine the sample (applying the inclusion criteria), select the articles and identify the categories for qualitative analysis.

To avoid bias in the analysis, the following internal screening and analysis protocol was followed: each researcher opened the files and proceeded to read the titles and the abstracts to verify that they came from refereed and indexed journals and that their subject 
matter was about digital competences in university teachers. Articles were included regardless of the focus and design of the study, in order to be able to look for research trends on the subject, as suggested by Bearman \& et al. [18] for systematic reviews in higher education.

\section{Results}

After reviewing the selected sample, it can be seen that scientific production in this field has become increasingly relevant over the years, highlighting that most of the documents that met the selection criteria were published mainly between 2018 and 2019 (Figure 2). These publications, which are distributed in the different corresponding quartiles in the databases (Scopus and WoS), are noteworthy for their low impact on this subject, as most of them received relatively few citations.

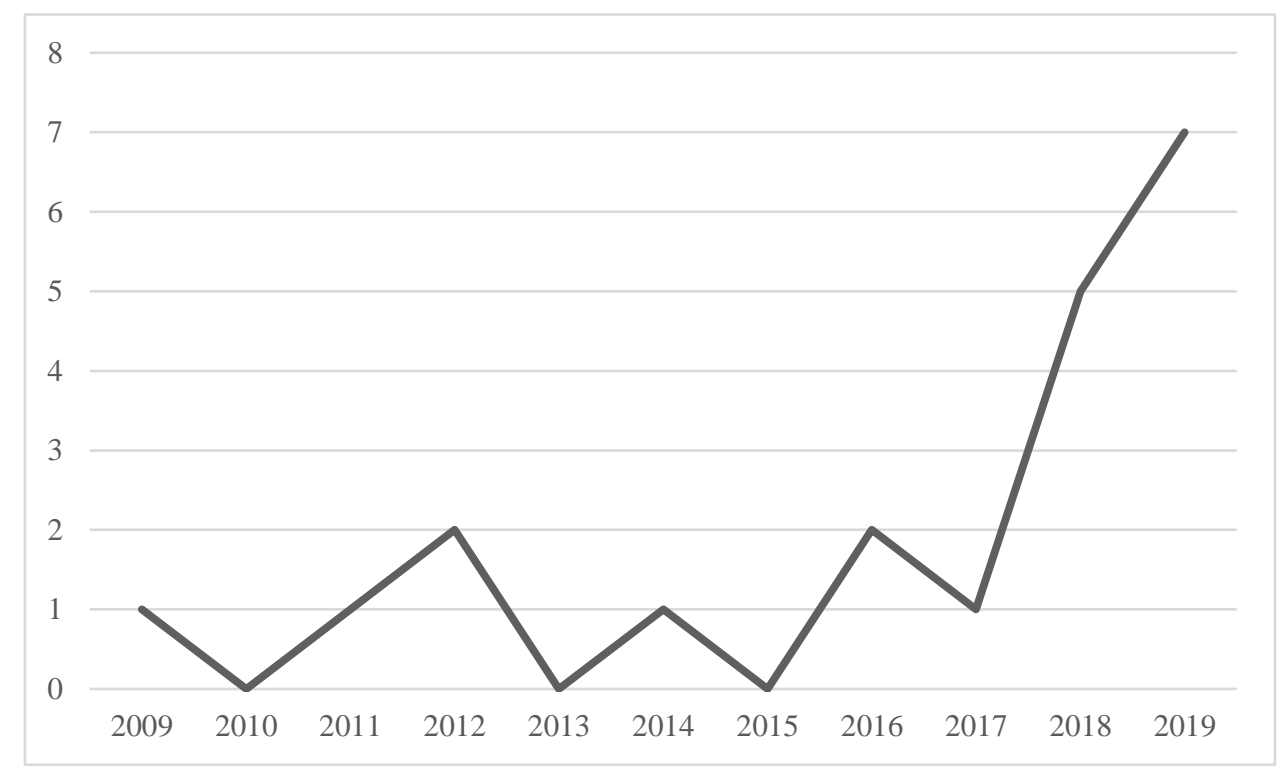

Figure 2. Article distribution per year.

This review has shown how research in this area of study is particularly interesting in many countries around the world. If we look at Figure 3, we can see how most of the scientific production has been carried out in Spain.

Regarding the type of methodological design used, we can see in Table S1 that most of the articles present a quantitative methodological approach (45\%), followed by those that present qualitative research $(30 \%)$ or mixed methods $(25 \%)$.

Focusing on the use of ICTs, we can see that teachers are very concerned about the integration of ICTs into university classrooms. From this perspective, it seems complicated to implement new teaching innovation models based on ICTs, because university teachers face several barriers, including, mainly, the lack of teacher training (30\%) or the teacher's profile (20\%); following that, there is the lack of experience $(15 \%)$ or resources $(10 \%)$. Among other barriers we can find lack of time (10\%) and, to a lesser extent, lack of support from institutions (5\%) due to economic problems $(5 \%)$ or problems with internet access (5\%) (Figure 4). 


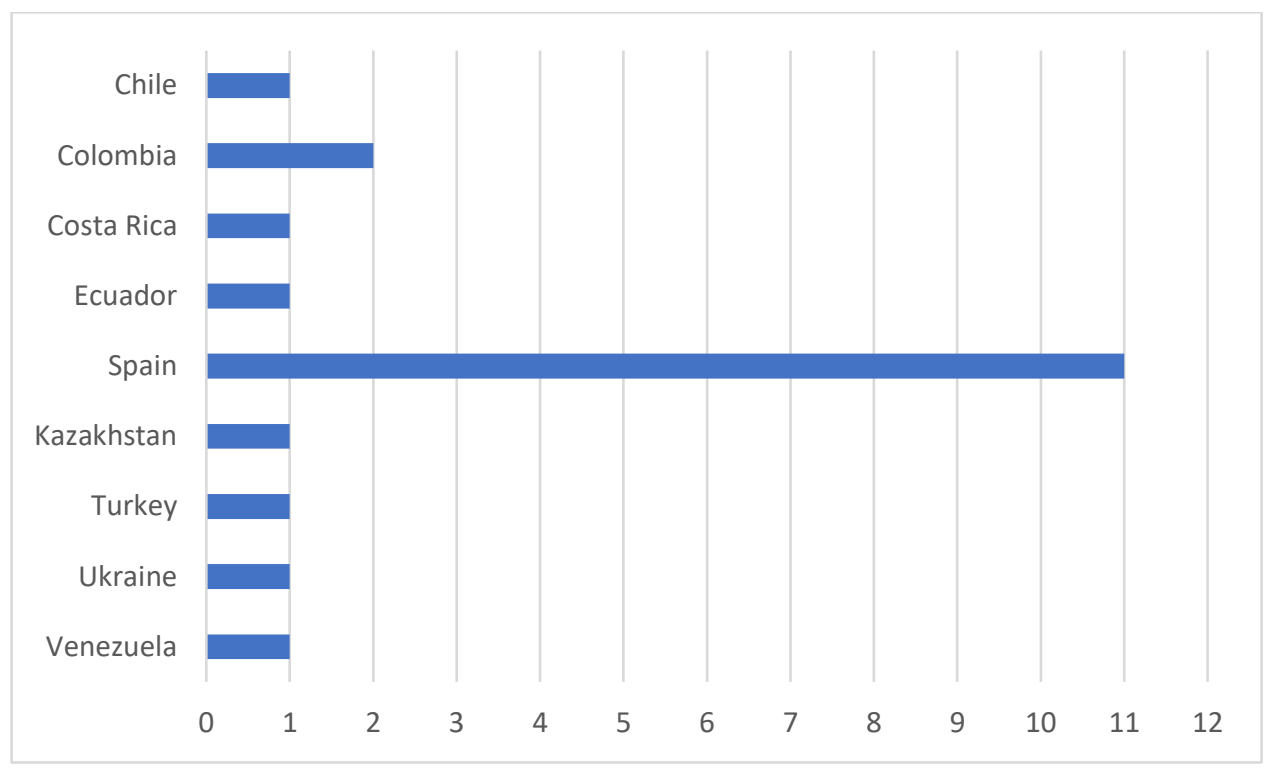

Figure 3. Article distribution per year.

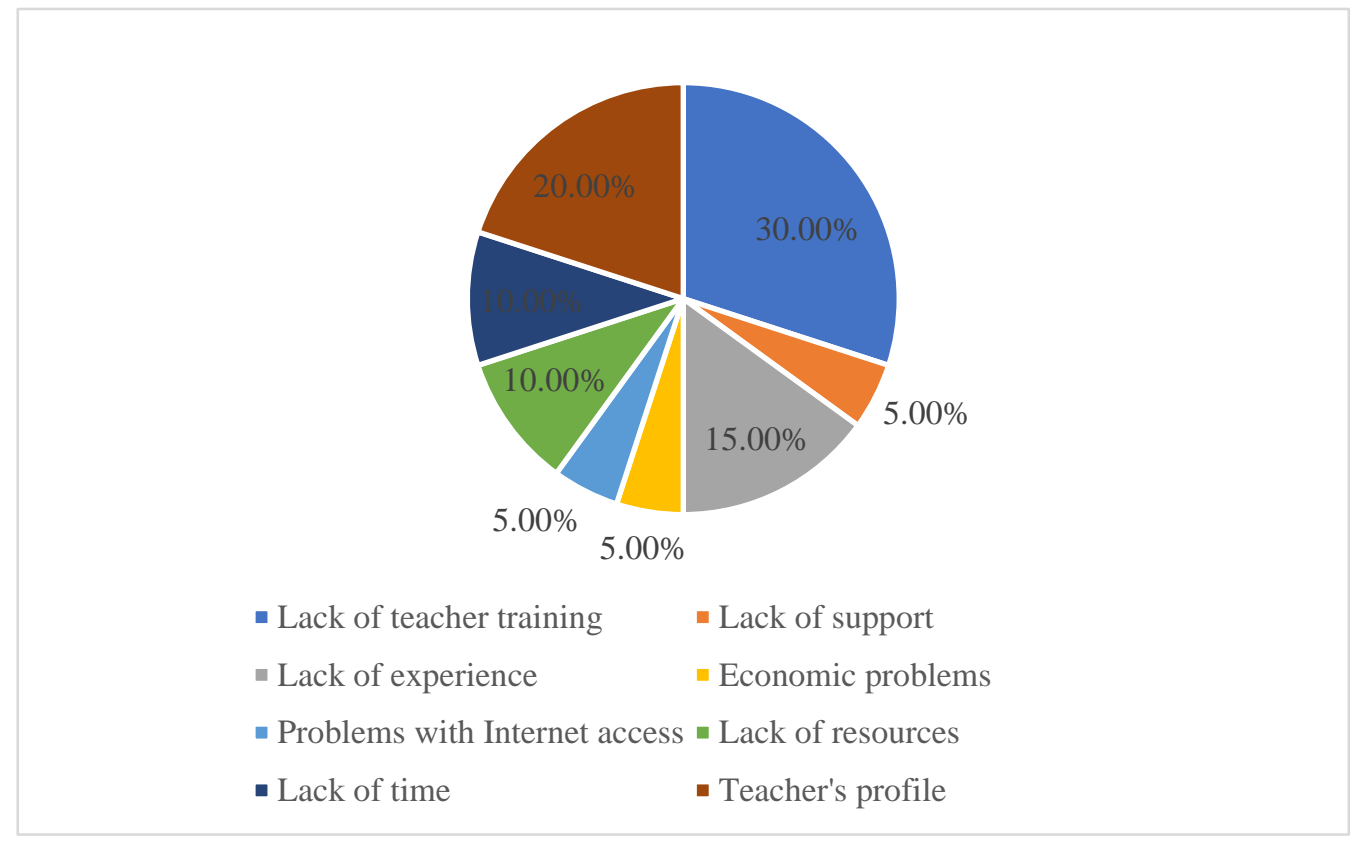

Figure 4. Hindering factors for the development of digital competences in teachers.

The digital skills training of university teachers is limited; the review revealed that they mainly use ICT for basic activities such as the presentation of visual resources (35\%) or for word processing programmes (25\%), followed by internet access $(20 \%)$. To a lesser extent, they are used for other more advanced applications $(10 \%)$, such as the creation and editing of digital resources $(10 \%)$.

In general, the articles point to the need to use ICTs in university classrooms, but that teachers need to be trained in digital skills.

Once the documents collected were analysed in a descriptive and quantitative way, the VOSviewer programme was used to analyse the relationships established between the keywords extracted automatically by Key Words Plus (KW+) from the different databases.

Among the 20 studies selected from the past decade, a total of $47 \mathrm{KW}+$ were extracted. In Figure 5, it can be seen how, according to similarity of the $\mathrm{KW}+$, three groups or clusters were established to define the main research topics in this field. The size of each circle or 
node represents the relevance that each descriptor has in this review, while the links or distance show the relations between nodes.

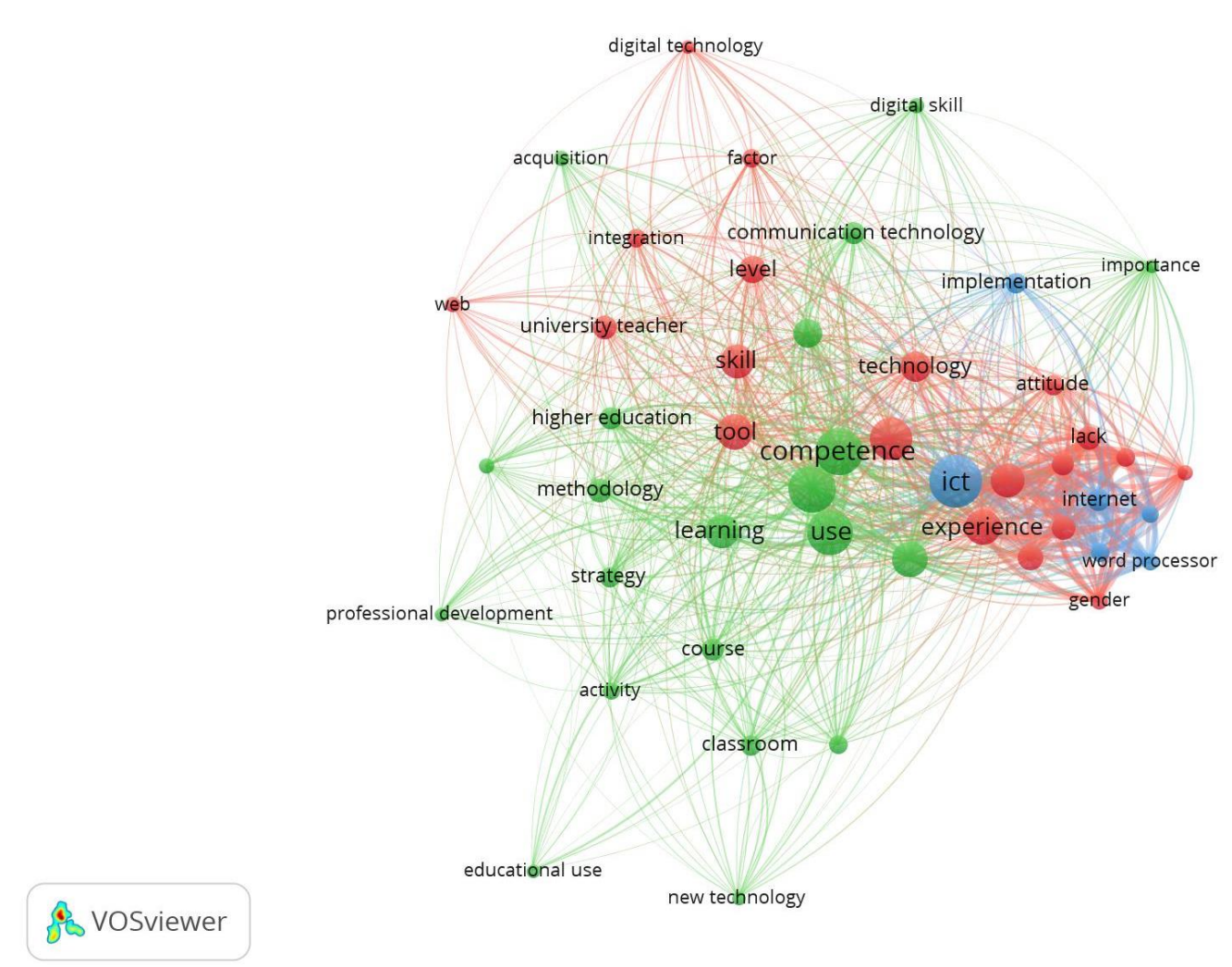

Figure 5. Labelled bibliometric map.

In relation to the three thematic clusters identified in the figure above, we can highlight:

Cluster 1: identified in red, is related to the challenges and barriers presented by university teachers to develop digital competence. Among the descriptors, we can find competence, skills, experience...

Cluster 2: represented in blue, is related to the main activities and applications developed by university teachers. The following descriptors are highlighted: word processor, internet, slide presentation...

Cluster 3: shown in green, is related to the importance of digital teacher training at the university stage. Among the descriptors, the following stand out: competence, university, use...

\section{Discussion}

The emergence of ICT has created new innovative settings in all societal sectors, including in the field of education. Thus, in order to achieve the objective of our review, the research questions posed above will be answered. Answering the first research question (Q1), in relation to the general state of scientific production in this field in the past decade, the main conclusion is that it is in an initial and expansion phase. Digital teaching competence is a field that, although it has been researched over time, is becoming more relevant and interesting over the past few years, since most scientific production has been published in recent years, with the aim of enabling teachers to achieve the skills and competences of the 21st century in order to develop experience and learning environments reinforced by technology [19].

In this regard, it is important to note that their integration at all educational levels, especially at the university level, has become an objective in various countries around the world, due, among other reasons, to the fact that these technological tools can improve the teaching and learning processes of students [20]. Likewise, in response to the second research question $(\mathrm{Q} 2)$, we can mention that scientific production in this field is becoming 
more relevant in different countries in America and Europe. Furthermore, it is evident that most of the articles located in this field are from Spain, an issue shared with previous studies $[13,21]$. Although this may be due to the use of search descriptors in both English and Spanish, there are few scientific publications worldwide. In view of this, researchers are encouraged to strengthen this important area of research in the 20th century [22].

Considering the third question (Q3), research in this field is becoming more relevant, although it is still scarce, as indicated by the low numbers of citations received by these articles; the majority did not receive any citations because they are quite recent publications. The aim of analysing studies with zero citations is to understand the skewed distribution of citations. There are a large number of articles with few or no citations, and a small number of highly cited articles [23].

In relation to research designs (Q4), articles with quantitative methodology prevail (45\%), followed by those with qualitative research (30\%) and to a lesser extent, studies using mixed methods (25\%). In this regard, a tendency or preference to use quantitative methods can be observed, where the main method used to collect information is the questionnaire, as found by other studies, such as the one carried out by Perdomo, González-Martínez \& Barrutia Barreto [13].

Regarding the last research question in this study (Q5), concerning the different difficulties faced by university teachers in the achievement of digital competences, we can say that universities are the base of educational innovation and knowledge transfer, so it is essential that they adapt the most innovative methodologies considering the digital technologies used nowadays [24]. However, all the publications reviewed recognised the lack of digital competence among university teachers, who have specific training needs in this area so that they can apply technology in classrooms [25-27].

The perception of university teachers regarding the use of ICTs in the classroom tends to show a positive attitude, since it should be one of the core competencies required by all teachers to carry out their profession $[19,28,29]$. However, its level of use and application is quite low [30]. Therefore, this calls for a reflection on training needs and whether they are suitable for handling different technological tools, both basic (word processor, tool handling or internet access) and more complex ones, such as the creation of technological and digital resources [25,31]. The use of these tools alone does not guarantee better quality in the teaching and learning process for students [32]. Other factors that affect their low use are lack of time, lack of resources or the predisposition of the teacher [33,34]. Less frequently, problems associated with internet access or the cost of resources are highlighted [35].

There seems to be more favourable perceptions of the use of ICTs if the institution supports their use, as happens in private universities as opposed to public ones, or the type of relationship with the university [30].

There were also training differences according to the teacher's profile, both in personal variables (gender and age) and in professional ones (professional teaching experience), as those with more experience required less training [25]. Finally, several authors report that women are more digitally literate, as are teachers under the age of 40 , who require less training [35].

\section{Conclusions}

We live in an increasingly changing world that requires education systems, along with education professionals, to rethink their teaching methods, adjusting them to current circumstances, that is, to the digital era. In this way, through this study, the aim has been to provide a general overview of the digital teaching skills in higher education through a systematic review of the relevant scientific literature in this area. But, after all that has been explained, we ask ourselves, is the university teacher really qualified in digital competences?

The scientific literature shows that university teaching staff are not sufficiently qualified in digital competences and are therefore not able to adapt their teaching methods to the demands of the current situation [12]. 
The findings of this systematic review will be used as the basis for recommendations regarding the training of university teachers, as well as for future research in this field. It is essential to continue with further research in this field, as ICTs are an essential element in education; yet production in this field is still scarce and merits an increase. This study confirms that more ICT teacher training means better training conditions for students [36,37]. Likewise, a proposal for permanent improvements must be drawn up so that teachers can develop digital teaching skills and be trained in both technological and pedagogical areas in new settings or using a combination of educational courses so that they can acquire the required digital skills [38-40], since the current and scarce training received by teachers causes a lack of motivation and little initiative to integrate ICT into the teaching-learning process [41]. Thus, one of the challenges for higher education is to take advantage of the full potential of ICT for learning, not only for the modernisation of educational institutions, but also for the improvement of the teaching-learning processes of students.

Supplementary Materials: The following are available online at https://www.mdpi.com/article/10 .3390 / educsci11110689/s1, Table S1: Characterisation of the articles included in the review.

Author Contributions: Conceptualization, J.M.F.-B. and E.L.-M.; methodology, M.M.-R. and P.R.-G.; software, M.M.-R. and J.F.-C.; validation, J.M.F.-B., P.R.-G. and E.L.-M.; formal analysis, J.M.F.-B. and M.M.-R.; investigation, M.M.-R. and J.F.-C.; resources, P.R.-G. and J.F.-C.; data curation, J.M.F.-B.; writing-original draft preparation, J.M.F.-B., P.R.-G., M.M.-R., J.F.-C. and E.L.-M.; writing-review and editing, J.M.F.-B., P.R.-G., M.M.-R., J.F.-C. and E.L.-M.; visualization, J.M.F.-B., P.R.-G., M.M.-R., J.F.-C. and E.L.-M.; supervision, J.M.F.-B., P.R.-G., M.M.-R., J.F.-C. and E.L.-M.; project administration, J.M.F.-B. and P.R.-G.; funding acquisition, J.M.F.-B. and P.R.-G. All authors have read and agreed to the published version of the manuscript.

Funding: This publication is part of the project I+D+i, PID2019-108230RB-I00, funded by MCIN/ AEI/10.13039/501100011033.

Institutional Review Board Statement: Not applicable.

Informed Consent Statement: Not applicable.

Conflicts of Interest: The authors declare no conflict of interest.

\section{References}

1. Alexander, B.; Ashford-Rowe, K.; Barajas-Murph, N.; Dobbin, G.; Knott, J.; McCormack, M.; Weber, N. EDUCAUSE Horizon Report 2019 Higher Education Edition; Educause: Louisville, CO, USA, 2019.

2. UNESCO. Enfoques Estratégicos Sobre las TIC en Educación en América Latina y el Caribe; OREALC-UNESCO: Santiago, Chile, 2014. (In Spanish)

3. Janssen, J.; Stoyanov, S.; Ferrari, A.; Punie, Y.; Pannekeet, K.; Sloep, P. Experts' views on digital competence: Commonalities and differences. Comput. Educ. 2013, 68, 473-481. [CrossRef]

4. European Commission. Marco Europeo de Referencia para las Competencias Clave del Aprendizaje Permanente; European Commission: Brussels, Belgium, 2004. (In Spanish)

5. Blau, I.; Shamir-Inbal, T. Digital competences and long-term ICT integration in school culture: The perspective of elementary school leaders. Educ. Inf. Technol. 2017, 22, 769-787. [CrossRef]

6. Cabero-Almenara, J.; Palacios-Rodríguez, A. Digital Competence Framework for Educators «DigCompEdu». Translation and adaptation of «DigCompEdu Check-In» questionnaire. EDMETIC Rev. Educ. Mediática Y TIC 2020, 9, $213-234$.

7. Hatlevik, O.E.; Throndsen, I.; Loi, M.; Gudmundsdottir, G.B. Students' ICT self-efficacy and computer and information literacy: Determinants and relationships. Comput. Educ. 2018, 118, 107-119. [CrossRef]

8. Cabero-Almenara, J.; Estrada-Vidal, L.; Gutiérrez-Castillo, J.J. Design and validation of an instrument for evaluation of digital competence of University student. Rev. Espac. 2017, 38, 1-16.

9. Mykhnenko, V. Cui bono? On the relative merits of technology-enhanced learning and teaching in higher education. J. Geogr. High. Educ. 2016, 40, 585-607. [CrossRef]

10. Carrillo, M.; Cascales, A.; Valero, A. Apps for foreign language learning at the University of Murcia. Rev. Educ. A Distancia 2018, $58,1-18$.

11. Ottenbreit, A.; Liao, J.; Sadik, O.; Ertmer, P. Evolution of Teachers' Technology Integration Knowledge, Beliefs, and Practices: How Can We Support Beginning Teachers Use of Technology? J. Res. Technol. Educ. 2018, 50, 1-23. [CrossRef]

12. Cabero-Almenara, J. University Teacher Training in ICT. Application of Delphi Method for the selection of training context. Educ. XX1 2013, 1, 111-131. 
13. Perdomo, B.; González-Martínez, O.A.; Barrutia Barreto, I. Digital competences in faculties: A systematic review. Rev. Educ. Mediática Y TIC 2020, 9, 92-115.

14. Grant, M.J.; Booth, A. A Typology of Reviews: An Analysis of 14 Review Types and Associated Methodologies. Health Inf. Libr. J. 2009, 26, 91-108. [CrossRef] [PubMed]

15. Moher, D.; Liberati, A.; Tetzlaff, J.; Altman, D.G.; Grupo PRISMA. Preferred reporting items for systematic reviews and metaanalyses: The PRISMA statement. PLoS Med. 2009, 6, e1000097. [CrossRef] [PubMed]

16. Conacyt. Consejo Nacional de Ciencia y Tecnología. 2020. Available online: http://www.apta.com.mx/apta2008/ce/dof/ descargapdf/2021/02Febrero/20210224/cnct21022410-7.pdf (accessed on 2 September 2021).

17. Knock, D.; Yang, S. Social Network Analysis; SAGE Publications: Thousand Oaks, CA, USA, 2007.

18. Bearman, M.; Smith, C.D.; Carbone, A.; Slade, S.; Baik, C.; Hughes-Warrington, M.; Neumann, D.L. Systematic review methodology in higher education. High. Educ. Res. Dev. 2012, 31, 625-640. [CrossRef]

19. Prendes Espinosa, M.P.; Gutiérrez Porlán, I. Technological competences of teachers in Spanish Universities. Rev. Educ. 2013, 361, $1-16$.

20. García Valcárcel, A.; Tejedor, F.J. Evaluación de los procesos de innovación escolar basados en el uso de las TIC desarrollados en la Comunidad de Castilla y León. Rev. Educ. 2010, 352, 125-147.

21. Reis, C.; Pessoa, T.; Gallego-Arrufat, M.J. Literacy and digital competence in Higher Education: A systematic review. Rev. Docencia Univ. 2019, 17, 45-58. [CrossRef]

22. Castellanos Adarme, M.E.; Nieto Sánchez, Z.C.; Parra López, H.M. Interpretation of the digital teaching competences in the university context. Logos Cienc. Tecnol. 2018, 1, 41-51.

23. Maestre Góngora, G.P. Literature review on smart cities: An ICT-centered perspective. Ingeniare 2015, 11, 137-149. [CrossRef]

24. Cabero, J.; Ballesteros, C.; López Meneses, E. The interactive concept maps as teaching resources in the university environment. Rev. Complut. Educ. 2015, 26, 51-76.

25. Muñoz, P.C.; González Sanmamed, M.; Fuentes, E.J. Technological skills of university teachers: Analysis of their training in computer office tools. Educ. XXI 2011, 14, 157-188.

26. Tejada-Fernández, J.T.; Pérez, K.V.P. New scenarios and trainers' digital competencies: Towards the professionalization of teaching with ICT. Profesorado 2018, 22, 25-51.

27. Alonso, R.R.; Plaza, I.R.; Orfali, C.H. Barriers in teacher perception about the use of technology for evaluation in higher education. Digit. Educ. Rev. 2019, 35, 170-185.

28. Mirete Ruiz, A.B. University teacher and ICT. A digital competence analysis. Ens.-Rev. Fac. Educ. Albacete 2016, $31,133-147$.

29. Suleimen, N. Appraising the attitude towards information communication technology integration and usage in Kazakhstani Higher Education Curriculum. J. Inf. Technol. Educ. Res. 2019, 18, 355-378. [CrossRef]

30. Riascos-Erazo, S.C.; Ávila-Fajardo, G.P.; Quintero-Calvache, D.M. Information Technology in the Classroom: The views of university professors. Educ. y Educ. 2009, 12, 133-157.

31. Pérez Díaz, R. Teaching digital competence in the teacher training institutes: Case of the Dominican Republic. Pixel-Bit Rev. Medios y Educ. 2019, 55, 75-97. [CrossRef]

32. Hidalgo-Durán, G. Technological competences development: Fundamental challenge for Costa Rican university teachers. Rev. Electrónica Calid. Educ. Super. 2019, 10, 34-52.

33. Fernández-Márquez, E.; Leiva-Olivencia, J.J.; López-Meneses, E. Digital competences in Higher Education Profesors. Rev. Digit. Investig. Docencia Univ. 2018, 12, 213-231.

34. Mercader, C.; Gairin Sallan, J. How do university teachers use digital technologies in class? Redu-Rev. Docencia Univ. 2013, 15, 257-273. [CrossRef]

35. Rodríguez Espinosa, H.; Restrepo Betancur, L.F.; Aranzazu, D. Digital literacy and learning management systems (LMS) in university teaching. Rev. Educ. Super. 2014, 43, 139-159.

36. Carrera Farrán, F.X.; Coiduras Rodríguez, J.L. Identifying the digital competence of university lecturers: An exploratory study in the field of Social Science. REDU-Rev. Docencia Univ. 2012, 10, 273-298. [CrossRef]

37. Palacios-Díaz, R.; Escudero-Nahón, A. The Training of Researchers with Digital Technologies: A Systematic Review of Specialized Literature. Res. Educ. Learn. Innov. Arch. 2012, 24, 23-38.

38. Mercader Juan, C. Resistances to use digital technologies in University teachers. Aula Abierta 2019, 48, 167-174.

39. Reyes Pérez, J.J.; Cardenas Zea, M.P.; Díaz Ocampo, E. Digital competences: A need for the Ecuadorian teacher of the XXI century. Dilemas Contemp.-Educ. Politica y Valores 2018, 6, 1-10.

40. Ríos Ariza, J.M.; Gómez Barajas, E.R.; Rojas Polanco, M.P. Valoración de competencias TIC del profesorado universitario: Un caso en Chile. Píxel-Bit. Rev. Medios y Educ. 2018, 55-65. [CrossRef]

41. Barroso Osuna, J.; Matos Alcantara, V.Y.; Aguilar Gavira, S. Analysis of the resources, uses and technological competences of the university teaching staff to understand and improve the learning process of the students. Rev. Iberoam. Educ. 2019, 80, 193-217. 